\title{
PRÁXIS EDUCATIVA E DISCURSIVA NO MOVIMENTO 21: TRANSGRESSÕES DE FRONTEIRAS E HIBRIDISMO EMANCIPATÓRIO
}

\author{
(Educational and discursive praxis in the 21 Movement: transgressions of boundaries and \\ emancipatory hybridism) \\ Claudiana Nogueira de Alencar ${ }^{1}$ \\ (Universidade Estadual do Ceará) \\ Sandra Maria Gadelha de Carvalho ${ }^{2}$ \\ (Universidade Estadual do Ceará) \\ José Ernandi Mendes ${ }^{3}$ \\ (Universidade Estadual do Ceará)
}

\begin{abstract}
In one of the states of Brazil, Ceará, in the highland area named Chapada do Apodi, a politicalacademic articulation, movimento 21 (M21), in English, the 21 Movement, has got together to fight against the economical pattern of agribusiness and its consequences related to the expulsion of the peasants and to the environmental degradation caused by the massive use of agro toxic products. The M21 movement is formed by several social movements and academic groups which have been articulated to struggle in favor of rural communities, this struggle is constructed based on discursive practices which aim to break up the traditional boundaries between academic and popular knowledge. The objective of this article is to understand, from a perspective of a decolonial theory and based on a rhetoric analysis taken as an approach of critical analysis, how the construction of Identification Meaning (FAIRCLOUGH, 2003) takes place in the discursive practices of the integrants of M21 movement. Through an ethnographic method built in public spaces in which the integrants of social movements, such as peasant men and women, educator, researches, religious leaders, political leaders and residents of Chapada do Apodi community, talk about violent deeds in the rural area against people and environment. In this article, it is discussed the identification-hybrid meanings aimed to the integrants of M21, taking the "boundary speech" and the "hybrid speech", which come across in those public meetings. It is also taken into consideration the multiplicity of interactional agents, the diversity of the educational praxis of each group involved with M21 and it is taken into account as well the decolonial literature, the analysis considers that the political implications of M21 points out an emancipatory and hybrid discourse.
\end{abstract}

Keywords: 21 movement, agribusiness, Pedagogy of the Oppressed, discursive practices, hybridism, boundaries, decolonial identities.

\section{RESUMO}

No estado do Ceará, na região da Chapada do Apodi, uma articulação político-acadêmica, o Movimento 21(M21), se organiza para o enfrentamento do modelo econômico do agronegócio e suas consequências relacionadas à expulsão dos camponeses e à degradação do meio ambiente com utilização massiva de agrotóxicos. O M21 é constituído por diversos movimentos sociais e grupos acadêmicos que se articulam em defesa das lutas das comunidades do campo, da Chapada do Apodi no município de Limoeiro do Norte, Ceará, por meio de práticas discursivas que pretendem romper com as fronteiras tradicionais entre os saberes acadêmicos e os saberes populares. $O$ objetivo deste artigo é compreender, a partir de uma perspectiva teórica descolonial e de uma proposta de análise críticodiscursiva, como se dá a construção de significados (FAIRCLOUGH, 2003) nas práticas discursivas

\footnotetext{
${ }^{1}$ Professora da UECE no Programa de Pós-Graduação de Linguística Aplicada (PosLA) e no Mestrado Acadêmico Intercampi em Educação e Ensino (MAIE).

${ }^{2}$ Professor da UECE no Mestrado Acadêmico Intercampi em Educação e Ensino (MAIE).

${ }^{3}$ Professora da UECE no Mestrado Acadêmico Intercampi em Educação e Ensino (MAIE).
} 
das(os) integrantes do M21. Por meio de etnografia realizada em espaços públicos em que militantes dos movimentos sociais, camponesas(es), educadoras(es), pesquisadoras(es), lideranças religiosas, lideranças políticas e moradoras(es) das comunidades da Chapada do Apodi falam sobre as ações de violência no campo contra pessoas e contra o meio ambiente, o artigo discute a constituição de significados híbridos para essa(e)s militantes por meio de um "falar da fronteira" que atravessam esses encontros. Levando em conta a multiplicidade de agentes em interação, a diversidade de práxis educativa de cada coletivo envolvido no M21, assim como a literatura descolonial, a análise considera que as implicações políticas do hibridismo presente nas práticas político-discursivas do M21 apontam para a constituição de um discurso de hibridismo emancipatório.

Palavras-chave: Movimento 21; agronegócio; pedagogia do oprimido; práticas discursivas, hibridismo, fronteiras, identidades descoloniais.

\section{INTRODUÇÃO}

O objetivo principal deste artigo é analisar as práticas discursivas de militantes que integram coletivo Movimento 21 e contribuir com uma reflexão sobre a práxis em torno de um novo projeto político, educacional e econômico para os povos do campo.

Em conformidade com o neoliberalismo hegemônico nas três últimas décadas no cenário internacional, percebe-se o avanço do capital no campo brasileiro, caracterizado pela expulsão dos trabalhadores rurais de suas terras, alteração do equilíbrio ambiental a partir do desmatamento das florestas naturais, ampliação da monocultura para exportação e uso massivo de agrotóxico na produção agrícola (CARVALHO e MENDES, 2014).

No Ceará, as comunidades da Chapada do Apodi nos municípios de Limoeiro do Norte e Quixeré, dentre elas a Comunidade do Tomé, que sobreviviam da prática da agricultura e comércio familiar, presenciam seu modo de vida modificar-se drasticamente. Terras públicas sob a responsabilidade do Departamento Nacional de Obras Contra as Secas (DNOCS) são ocupadas pelo agronegócio, com o apoio do Estado através de incentivo direto à ocupação e também omissão quanto aos processos de transgressão da lei verificados na posse da terra quanto, posteriormente, no uso abusivo de agrotóxicos, que provoca o envenenamento da água e dos moradores das comunidades da Chapada.

Em nossas pesquisas de campo ligadas à linha de pesquisa Trabalho, Educação e Movimentos Sociais, do Mestrado Acadêmico Intercampi em Educação e Ensino (MAIE), situado no campus de Limoeiro do Norte na Faculdade de Filosofia Dom Aureliano Matos (FAFIDAM) e à linha Estudos Críticos da Linguagem no Programa de Pós Graduação em Linguística Aplicada (PosLA) em Fortaleza, temos acompanhado diversas instituições, entidades e movimentos sociais que têm procurado resistir à lógica de desenvolvimento fundada no agronegócio exportador, através da denúncia dos problemas agrários, sanitários e ambientais, seguidas de mobilizações políticas dos coletivos envolvidos. Este modelo, que 
intensifica a exploração dos recursos naturais, é também marcado pela "alta concentração da terra, modernização no maquinário agrícola, constituição de massa de assalariados e incremento de insumos que elevem a produtividade" (CARVALHO e MENDES, 2014).

Desse modo, resolvemos investigar o Movimento 21 (M21), que surge como uma expressão de resistência a esse modelo, agregando diversos militantes oriundos dos movimentos sociais do campo, setores da Igreja Católica vinculados à Teologia da Libertação, organizações de esquerda, ambientalistas e pesquisadores das universidades públicas (Universidade Estadual do Ceará-UECE e Universidade Federal do Ceará-UFC).

O M21 foi constituído após o assassinato do líder comunitário e ambientalista, José Maria Filho, conhecido por José Maria do Tomé, e tem como objetivo o enfrentamento do modelo do agronegócio e suas consequências relacionadas à expulsão dos camponeses, a degradação do meio ambiente com utilização massiva de agrotóxicos. Zé Maria foi assassinado por denunciar a apropriação ilegal das terras pelo agronegócio e o envenenamento dos mananciais d'agua, do ar e dos alimentos. Em continuação a luta de Zé Maria o M21 denuncia ainda a grilagem de terras às necessidades do mercado e criminalização dos movimentos sociais que se expande na Chapada do Apodi, na fronteira dos estados do Ceará e do Rio Grande do Norte. A denominação do movimento se constitui em uma homenagem ao ambientalista e memória ao dia 21 de abril de 2010, data em que Zé Maria do Tomé foi assassinado.

Utilizamos como metodologia a perspectiva metodológica etnográfica, considerando o que nos diz Magalhães (2000, p. 48): "o estudo do discurso devidamente contextualizado se realiza de forma mais adequada com métodos etnográficos”. Quanto às técnicas de pesquisa, foram utilizadas quatro entrevistas semiestruturadas, observação participante e notas de campo (relatos de pesquisa), oficinas, artefatos (textos) e fotos. Este artigo analisa dados de observação participante e relatos de pesquisa de uma audiência pública e de uma oficina promovida pelo M21, além de um almanaque, material didático produzido pelo movimento. Os dados gerados permitiram analisar a práxis educativa e discursiva no movimento 21 a partir das transgressões de fronteiras entre saberes hegemônicos e saberes contra hegemônicos.

\section{PRÁXIS, DISCURSO E IDENTIDADE}

A práxis é uma categoria chave para o entendimento das atividades humanas, relacionada à compreensão, interpretação, produção simbólica e intervenção na realidade sócio histórica. Segundo Vázquez (1977, p. 3) práxis é a "atividade material do homem que transforma o mundo natural e social para fazer dele um mundo humano". 
Marx (2015) dá fundamentos a esta perspectiva, quando apresenta um entendimento de que através da prática ontológica sobre a natureza o ser humano, não só a transforma, mas transforma a si mesmo e num processo contínuo de interações se forma a partir de práticas sociais diversas. Daí, que tanto um como outro autor negam a objetivação do ser humano como algo determinado unilateralmente pela realidade objetiva. A "atividade própria do homem não pode reduzir-se a sua mera expressão exterior, e, que ela faz parte essencialmente da atividade da consciência” (VÁZQUEZ, 1977, p. 191).

É na luta pela sobrevivência, nas interações, inclusive, conflitos entre grupos e classes, que os seres humanos vão construindo suas interpretações, visões e práticas sociais, descobrindo, inclusive, o lugar dos discursos e das identidades. "É na práxis e pela práxis que o homem enquanto ser social transforma seu meio e se autotransforma, se recria, ou seja, na luta pela sobrevivência o homem transforma suas condições sociais da vida que é, ao mesmo tempo, autocriação e criação coletiva de si mesmo" (CARVALHO, PIO \& MENDES, 2014, p. 2).

A categoria práxis questiona as dicotomias ser humano-mundo, matéria-espírito, teoriaprática, sujeito-objeto, discurso-realidade, essência-aparência. Enquanto forma específica do ser humano, a práxis "torna-se uma atividade transformadora, criadora, autocriadora, uma atividade que produz, forma e transforma o homem social, seu meio, sua consciência e suas ações no mundo real" (CARVALHO, PIO \& MENDES, 2014, p. 6).

Ao processo de transformação, interligado à noção de práxis, articulamos a perspectiva discursiva de Norman Fairclough (2001). Para Fairclough, o discurso afeta a realidade social e é afetado por esta em uma relação dialética. Por esta visão, o discurso é considerado como uma prática social e política. Conforme Magalhães, podemos considerar essas práticas como "formas de atividades sociais que apresentam relativa estabilidade, formadas de diversos elementos, entre os quais o discurso (semiose) [...] ações, sujeitos e relações sociais, instrumentos, objetos, tempo e lugar, formas de consciência, valores" (MAGALHÃES, 2004, p. 114-115).

Desse modo, o discurso, como parte de práticas sociais, atua de três modos, concebidos por Fairclough (2003) como significados: o discurso é modo de ação (significado acional), um modo de representação (significado representacional) e um modo de identificação (significado identificacional). Neste artigo, delimitamos os significados do discurso como categorias de 
análise - o significado acional, o significado representacional e o significado Identificacional (FAIRCLOUGH, 2003).

O significado acional diz respeito aos gêneros textuais ou discursivos, uma vez que os gêneros se apresentam como modos de interação em eventos sociais. Cada prática social produz e utiliza gêneros discursivos particulares, que articulam identidades e discursos de maneira relativamente estável num determinado contexto sociohistórico. Para estudar os significados acionais estudaremos o gênero discursivo de modo situado, como categoria concreta, sendo para isso delimitados os seguintes gêneros discursivos: audiência pública e oficina, específicos das prática discursivas das lutas políticas próprias de territórios populares organizados.

No que diz respeito ao significado representacional, analisamos os discursos, entendidos como formas de "construir aspectos do mundo associados a uma perspectiva social particular" (FAIRCLOUGH, 2009, p. 163). Assim, procederemos a identificação dos discursos articulados e da maneira como são articulados nos relatos de pesquisa e nas entrevistas.

Quanto ao significado identificacional, podemos dizer que constitui o aspecto discursivo de identidades, pois relacionam-se com a identificação de atores sociais em textos e com a forma como os textos adotam posições constituídas e articuladas intersubjetivamente (FAIRCLOUGH, 2003). Para estudar esse processo de identificação no discurso, analisaremos, neste artigo, a categoria discursiva da “avaliação' que está relacionada à natureza da atitude de falantes, no tocante ao seu julgamento, afeto e apreciação (FAIRCLOUGH, 2003; WHITE, 2011).

Nas duas seções seguintes, buscamos proceder a análise dos três significados de forma articulada:

\section{SIGNIFICADOS ACIONAIS: HIBRIDISMOS E VOZES MÚLTIPLAS NAS OFICINAS DO M21}

O discurso apresenta-se como um modo de agir, constituindo significados acionais nas ações e interações que ocorrem em eventos sociais. No que diz respeito ao Movimento 21, identificamos dois gêneros utilizados como modo de luta: a oficina e a audiência pública. Nesta seção, procuraremos examinar a oficina, como um dos gêneros próprios da prática discursiva do M21.

Como a aula, a oficina é um gênero que resulta de realizações linguísticas concretas. No entanto, enquanto a aula expositiva segue um roteiro estabelecido anteriormente com base no conhecimento científico, a oficina é um gênero que busca a construção do conhecimento com ênfase na ação e na experiência, sem contudo, desprezar o saber teórico. Como nos dizem 
Paviani e Fontana (2009, p. 78), "numa oficina ocorrem apropriação, construção e produção de conhecimentos teóricos e práticos, de forma ativa e reflexiva".

Após várias pesquisas ${ }^{4}$ que demonstravam as consequências nefastas da implantação das agroindústrias na Chapada do Apodi, surgiu a preocupação com a divulgação destes trabalhos. Relata Ferreira (2012) que os próprios movimentos sociais envolvidos sugeriram a formação de um grupo de sistematização, composto por acadêmicos e ativistas que teria a instigante função de pensar esta tarefa.

Assim, no mesmo ano, em 2011, ocorreu a oficina no Seminário Diocesano de Limoeiro do Norte, para pensar como seria a metodologia de partilha com a sociedade destes conhecimentos.

No início da Oficina os movimentos prepararam uma mística ${ }^{5}$ para sensibilizar e refletir com todos a função social dos conhecimentos. Com livros dispostos em uma mandala, no chão da sala, juntamente com instrumentos de trabalho e elementos da produção agrícola, tais como terra e sementes, uma militante lia um texto sobre o diálogo entre o conhecimento popular e científico.

No primeiro dia se reconstruiu a linha do tempo da Chapada, com a participação dos movimentos sociais e estudiosos da Universidade Estadual do Ceará e Universidade Federal do Ceará. Cada pessoa pegava uma tarjeta e escrevia o que sabia sobre os acontecimentos de determinado período na Chapada e no Brasil, e assim construímos uma retrospectiva das transformações ocorridas naquele território até os dias atuais. A seguir, com base nos relatos de observação etnográfica e entrevistas, faremos um breve relato sobre essa retrospectiva traçada pelos participantes do M21:

A partir do adoecimento das crianças e moradores, da mortandade de animais, os próprios residentes na Comunidade do Tomé e participantes da associação comunitária local, levantaram a hipótese da água está causando tais males. Levaram a questão para reuniões com assessores da Cáritas Diocesana de Limoeiro do Norte, a qual atua no local. Foi então que essa instituição demandou a professora Dra. Raquel Rigotto, do Departamento de Saúde Comunitária do Curso de Medicina da Universidade Federal do Ceará (UFC) e coordenadora do Núcleo Trabalho, Meio Ambiente e Saúde para a Sustentabilidade (TRAMAS/UFC) uma

${ }^{4}$ Ferreira, Marcelo José Monteiro (2012), em sua dissertação de mestrado enumera nove trabalhos entre dissertações, monografias e teses de doutorado, além da pesquisa da Profa. Raquel Rigotto,

${ }^{5}$ A mística é uma prática discursiva, cultural e política das trabalhadoras e trabalhadores do MST (Movimento dos Trabalhadores Sem Terra), vivenciada na abertura de seus encontros, reuniões, aulas, círculos, etc. Ela funciona como um ritual coletivo em que se misturam diversas linguagens: teatro, música, poesia dentre outros. 
pesquisa para averiguação das reais consequências da aplicação de agrotóxico por via aérea para a saúde dos atingidos. A referida professora desenvolveu a pesquisa "Estudo epidemiológico da população da região do Baixo Jaguaribe exposta à contaminação ambiental em área de uso de agrotóxicos" (Edital MCT- CNPq / MS - SCTIE / CT - Saúde - nº 24/2006. Por meio desta pesquisa foi possível detectar o envenenamento de pessoas e da água que abastece a comunidade, pois os canais, por meios dos quais é realizado o abastecimento, não têm cobertura e assim são suscetíveis à pulverização.

De forma empírica, os moradores da Chapada passaram a observar fatos incomuns associados aos dias de pulverização aérea do agrotóxico. Assim, Mariana ${ }^{6}$, residente na Comunidade do Tomé, relata: no dia que passava o avião, tudo ficava branco, parecia que tava nevando... as crianças ficava com a pele irritada, grossa, avermelhada.

Nas linhas do tempo, os participantes narraram os trabalhos, a vida e a luta do José Maria, líder comunitário ambientalista, assassinado por denunciar o envenenamento das comunidades da Chapada pelo uso indevido dos agrotóxicos. Aqui trouxemos um trecho do relato da fala dos ativistas João e Fátima:

João: Zé Maria foi morto no dia 21 de abril de 2010 com 25 tiros, disparados de maneira covarde, pelas costas. Já passou um ano e os assassinos ainda tão soltos.

Fátima: O companheiro foi morto pelo o agronegócio, pois defendia o fim da pulverização de uma área na chapada do Apodi.

A seguir transcrevemos trecho de uma entrevista, em que uma pesquisadora relata o segundo dia daquelas oficinas:

No segundo dia, após uma nova mística, desta feita na sombra de uma mangueira, no pátio externo do seminário, cantamos e nos emocionamos com a possibilidade concreta de todas juntos estarmos tentando construir uma nova realidade com seus saberes e uma boa dose de humildade.

A pergunta geradora dos trabalhos foi: o que divulgaríamos e como? Tarefa nada fácil devido a tentas produções. Os movimentos tiveram fala preponderante neste quesito pois faziam sempre menção ao que julgavam de mais importante o povo deveria saber. Os acadêmicos presentes também opinavam. Mais difícil, foi depois desse recorte, decidir o como, pois então haveria diversas formas de entrelaçar os conhecimentos.

Depois de muitas reflexões decidiu-se pela feitura de um almanaque, com um roteiro para o qual participantes dos movimentos e pesquisadores se

\footnotetext{
${ }^{6}$ Todos os nomes são fictícios resguardando o anonimato do(a)s participantes da pesquisa.
} 
encarregavam por determinadas partes. Desta maneira, e em outras oficinas com sistemática semelhante foi construído o "Almanaque do Baixo Jaguaribe ou TRAMAS para a afirmação do trabalho, meio ambiente e saúde para a sustentabilidade". Do qual consta os nomes de todos atividades e acadêmicos que contribuíram na sistematização e construção.

Em termos de análise do significado acional, podemos analisar os dados gerados e apresentados anteriormente, a partir do estudo de Fairclough (2003) sobre a articulação de vozes em textos. Para Fairclough questão pertinente à análise da intertextualidade é a investigação de quais vozes são incluídas e quais são excluídas, em uma abordagem das ausências significativas.

Nos trechos acima, o M21 focaliza, através do gênero oficina, a copresença das vozes de indivíduos representantes de vários movimentos: Cáritas Diocesana da igreja católica em Limoeiro do Norte; Movimento dos Trabalhadores Rurais Sem Terra (MST); representantes do Movimento dos Atingidos por Barragens (MAB) e do Movimento dos Pequenos Agricultores (MPA); Associação dos Moradores do Tomé - comunidade do município de Limoeiro do Norte, localizada na Chapada do Apodi; Sindicato dos Funcionários públicos de Limoeiro do Norte; Rede Nacional de Advogados e Advogadas Populares (RENAP); e, grupos acadêmicos, envolvendo professores e alunos da Universidade Federal do Ceará (UFC), através do Grupo Trabalho Meio Ambiente e Saúde para a Sustentabilidade (TRAMAS) ${ }^{i}$ e da Universidade Estadual do Ceará (UECE), pelo envolvimento da Faculdade de Filosofia Dom Aureliano Matos (FAFIDAM), através do Laboratório de Estudos da Educação do Campo (LECAMPO) situado neste campus da UECE, em Limoeiro do Norte.

No coletivo, cada indivíduo, por sua vez, representa um outro coletivo, diferenciando as pessoas de diversas maneiras, o que significa um trabalho de orientação para a diferença, ao dar voz ao Outro em seu discurso, fator fundamental para a interação social. Segundo Fairclough (2003), a produção da interação acarreta a negociação ativa e continuada da diferença de sentido, negociando diferenças ao representar diferentes atores sociais e a negociação de suas diferenças. No coletivo, diferentes vozes, como nos relatos acima em que vozes de pesquisadores e vozes dos ativistas dos movimentos sociais foram relatadas, nos recontarão articuladas na linha de tempo da história de luta da Chapada do Apodi e na construção de um artefato textual de visibilidade da luta e divulgação das pesquisas: o Almanaque do Baixo Jaguaribe. Nessa construção, diversos conflitos de natureza ideológica, política e teórica são constantemente negociados. 
Esse hibridismo de vozes é de certo modo, possibilitado pelo próprio hibridismo presente na estrutura genérica das oficinas do M21. Nela, outros gêneros como a mística, a canção, o depoimento, a roda de conversa se misturam, constituindo os significados acionais da oficina, estratégias de sistematização e trabalho coletivo do M21.

Outro gênero discursivo utilizado nas lutas do Movimento 21 é a audiência pública. Gomes (2001) estuda o gênero discursivo "audiência pública”, mostrando como sua estrutura genérica abre-se para temas da democracia cidadã e da participação popular nas decisões do Estado. Segundo a autora, a audiência pública está estruturada de modo a favorecer o hibridismo discursivo e político: são utilizados diversos gêneros, estilos e representações de mundo (discursos) por parte dos participantes das audiências públicas para alcançarem seus objetivos de luta coletiva. Na próxima seção, analisaremos os discursos de fronteira entre saberes populares e saberes científico constituintes das audiências públicas do M21. Para isso, serão utilizados relatos de pesquisa e entrevistas.

\section{SIGNIFICADOS REPRESENTACIONAIS E IDENTIFICACIONAIS: FRONTEIRAS ENTRE DISCURSOS POPULARES E CIENTÍFICOS NAS AUDIÊNCIAS DO M21}

As audiências públicas são requisitadas por parlamentares, que as solicitam por iniciativa própria ou em resposta aos sujeitos sociais, individuais ou coletivos. Muitas vezes são os próprios movimentos sociais que demandam a determinado parlamentar audiência para discutir uma temática que se constitui um problema social. Neste caso, o presidente das casas legislativas, tanto Câmara de Vereadores, como Assembleias de Deputados Estaduais ou Federais, convidam representantes dos movimentos, entidades e sociedade civil envolvida com a questão para discussão e pronunciamento agendados previamente. Trata-se de eventos públicos, que embora contem com a formalidade de pronunciamentos de sujeitos convidados previamente, em muitos casos, a palavra é também facultada aos presentes. Os pronunciamentos e discussões têm o propósito de buscar a interveniência e medidas do poder público sobre a questão. São espaços que, ao exporem contradições sociais, podem favorecer a ampliação da democracia à medida que o Estado, no sentido conferido por Gramsci, no qual a sociedade civil se torna território de disputa, é tensionado, por pressões ao governo, para que este tome decisões políticas com vista à garantia de direitos, no caso em apreço, à saúde, à moradia, à terra para o trabalho (Carvalho \& Mendes, 2014).

No contexto dos movimentos sociais e do Movimento 21 da microrregião do Baixo Vale Jaguaribe, especificamente no município de Limoeiro do Norte, podemos destacar em meio às 
diversas e contínuas lutas por direito e justiça socioambiental, duas audiências que mobilizaram a sociedade civil em torno da resistência à pulverização aérea no Perímetro Irrigado JaguaribeApodi. A primeira, no âmbito da Câmara dos Vereadores de Limoeiro do Norte, ocorreu em maio 2010, dias após o assassinato do Zé Maria do Tomé, e, a segunda, no âmbito da Assembleia Legislativa do Estado do Ceará, requerida pelo deputado Renato Roseno, do PSOL, ocorreu em abril de 2015 em Fortaleza. Ambas foram audiências que tiveram grande participação popular, contando com centenas de pessoas. Também participaram representantes dos poderes Legislativo e atores do Ministério Público Estadual, Diocese e Cáritas Diocesana de Limoeiro do Norte, LECAMPO/FAFIDAM/UECE, TRAMAS/UFC, Central Sindical CSP CONLUTAS e alguns militantes e simpatizantes do Partido Socialismo e Liberdade (PSOL) e do Partido Socialista dos Trabalhadores Unificados (PSTU) dentre outros.

No bojo destes momentos formativos propiciados pelas audiências e outras ações políticas, a temática ambiental, agroecologia e agricultura familiar, se apresenta como alternativa ao modelo do agronegócio, que abusa no uso massivo de agrotóxicos a despeito do malefício que causa às populações e ao ambiente em que moram e trabalham. As audiências amplificam a questão da gravidade da pulverização aérea e provocam sujeitos sociais e representantes governamentais a efetivarem ações políticas, possibilitando grande aprendizado na práxis. Uma das principais implicações é a superação do medo das trabalhadoras e dos trabalhadores em enfrentarem a lógica violenta do agronegócio, utilizando neste enfrentamento o seu discurso nas audiências. Outra importante implicação é a desmitificação do discurso do progresso que esta lógica desenvolvimentista faz circular.

Para entender esse conflito entre discursos, utilizamos o significado representacional como categoria relevante nesta pesquisa, uma vez que os discursos presentes nas falas das pessoas presentes foram os principais focos das audiências acima citadas. A seguir, apresentaremos alguns trechos relevantes destacados no levantamento de dados, durante a Audiência Pública de 24 de abril de 2015, na Assembleia Legislativa do Estado do Ceará:

Trecho 1: Nós somos representantes das comunidades do Jaguaribe, da Chapada do Apodi e nós somos a região mais atingida com a questão de agrotóxico. (Líder comunitária)

Trecho 2: Isso tem agravado muito a saúde da nossa região. A comunidade recebe água diretamente do canal então o canal é aberto. Quando os aviões passam eles poluem a água que 
vai para a comunidade que vai para a casa das pessoas. E isso tem influenciado nos inúmeros casos de aborto inúmeros casos de câncer, de crianças que estão nascendo com má formação. (Representante da Cáritas - Limoeiro do Norte)

Trecho 3: Eu lembro do companheiro Zé Maria quando dizia daqui a 10 anos talvez eu não esteja vivo, mas vocês vão ver o número de câncer na região. (Membro das Comunidades da Chapada)

Trecho 4: A história do Zé Maria se confunde com a história dos pequenos camponeses lá da Chapada ele foi desapropriado para dar lugar ao Projeto de irrigação, quer dizer uma reforma agrária ao contrário. (Vereador do Psol):

Trecho 5: A gente está com o número altíssimo de casos de "cancers" na comunidade, 4h da tarde a gente olhava para a comunidade e via tudo branco, a gente olhava e nem a igreja a gente não via, tudo branco. (Membro das Comunidades da Chapada)

Trecho 6: Eu tinha um quintal com 120 galinhas e morreram 80 galinhas numa tarde só quando o avião passou expurgando. (Membro das Comunidades da Chapada)

Trecho 7: Queremos aqui denunciar que tem gente trabalhando de forma análoga à escravidão. Isso não é uma questão de discurso ideológico isso é uma realidade concreta. Nós estamos no meio do povo. Nós estamos juntos com o projeto de lei. Estamos juntos contra a pulverização aérea totalmente. (Militante do MST)

Em termos de significado representacional entendido como discurso ou formas de representar a realidade, podemos perceber a presença da heterogeneidade discursiva na audiência pública, na medida em que reconhecemos, na prática discursiva do Movimento 21 (produção, distribuição e consumo de textos) a articulação de diferentes discursos. A essa articulação da diferença, dá-se o nome de interdiscursividade. Desse modo, percebemos na fala dos membros da comunidade tanto o discurso que valoriza os saberes populares, quanto o discurso de valorização dos saberes científicos. É assim que encontramos nos trechos 2, 3, 5 e 6 a valorização da memória (Eu lembro do companheiro Zé Maria quando dizia), da narrativa 
(4h da tarde a gente olhava para a comunidade e via tudo branco), da experiência (Eu tinha um quintal com 120 galinhas e morreram 80 galinhas numa tarde só), mas também percebemos nos mesmos trechos, termos que remetem ao discurso científico: má formação, câncer, agrotóxicos.

As falas das lideranças e membros da comunidade mostram a utilização de uma retórica da fronteira como um modo de ação política. As denúncias das lideranças das comunidades da Chapada do Apodi eram deslegitimadas pelo poder público com argumento de que as manifestações contrárias ao uso do agrotóxico na região não estavam embasadas cientificamente. Por isso, Zé Maria do Tomé e outras lideranças buscaram as universidades federal e estadual para pesquisarem sobre o tema. Os resultados dessas pesquisas como vimos foi sistematizado coletivamente por meio das oficinas. Desse modo, a comunidade, sem abrir mão de suas práticas populares tradicionais se apropria do discurso científico passando agora a utilizar um falar de fronteira entre saberes populares e científicos em sua práxis cotidiana contra os abusos do agronegócio. Friedman (2001, p.9) se refere à retórica da fronteira para dizer que "as fronteiras fixam e demarcam, mas, em si mesmas, são linhas imaginárias fluidas e em permanente processo de transformação". Segundo a autora, as fronteiras, quer sejam literais ou figuradas, funcionariam como conjuntos binários em que se combinam o mesmo e o diferente, o dentro e o fora, o "nós" e o "eles". Trabalhar discursivamente neste "entre-espaços" tem sido o desafio do movimento que se utiliza da retórica da fronteira, ou seja, ora se utiliza do discurso da experiência, do saber popular, como na fala do militante dos movimentos campesinos, no trecho 7 (Isso não é uma questão de discurso ideológico isso é uma realidade concreta. Nós estamos no meio do povo); ora usa os dados resultantes das pesquisas científicas, como no trecho 5 (A gente está com o número altíssimo de casos de “cancers” na comunidade).

Para o semioticista Walter Mignolo, pensar fronteiriço é uma "maneira de ser e de existir de todos aqueles e aquelas que habitam o border". Para o autor, o pensar fronteiriço permite a construção de projetos que apontam para outras formas de vida para além da colonialidade.

O conceito de colonialidade do poder ${ }^{7}$ foi desenvolvido pelo sociólogo peruano Aníbal Quijano (2009, p. 73) para entendermos o seu funcionamento como um elemento constitutivo e específico do padrão mundial do poder capitalista. Na mesma linha de pensamento, Maldonado-Torres (2009) analisa o caráter preferencial da violência como colonizador do ser

\footnotetext{
${ }^{7}$ Para Ramón Grosfoguel ( 2009) como fim das “administrações coloniais” e a independência dos Estados-nação "os povos não-europeus continuam a viver sob a rude exploração e dominação europeia/euro-americana" passando do "colonialismo global" para um período de "colonialidade global".
} 
que se traduz, por meio da colonialidade, na relação entre o racismo, a exploração capitalista, o monopólio do saber, o domínio sexual e a história colonial moderna. Para Mignolo é o pensar fronteiriço que pode subverter a colonialidade do ser, fazendo com que as identidades subalternas se tornem transgressivas dos padrões da colonialidade. Ele diz:

Neste momento, a consciência e o ser de fronteira transformam-se no pensamento fronteiriço em ação, colocamos a experiência e o pensamento em ação. Alguns chamam isto de pensamento [ou posicionamento] crítico fronteiriço. O "crítico" está sobrando porque o pensamento fronteiriço em ação é necessariamente crítico e decolonial (MIGNOLO, 2000, s/p).

É assim que podemos entender o falar da fronteira como crítico e decolonial. No caso das práticas discursivas do M21, esta retórica da fronteira possibilidade a construção de um engajamento híbrido, aliando a experiência dos povos da Chapada, com o pensamento científico desenvolvido pelos pesquisadores da universidade, constituindo uma nova identidade militante. Desse modo, entendemos que os gêneros discursivos próprios das práticas discursivas do M21, como as oficinas e as audiências públicas, indicam que as(os) integrantes do movimento constituem identidades subalternas descoloniais. Segundo Mignolo (2000), a colonialidade é constituída por um pacote epistêmico que inclui as "ficções imperiais raciais, genéricas e sexuais e as ficções imperiais em torno do Terceiro Mundo, países desenvolvidos, economias emergentes. Este é um pacote epistêmico que justifica o controle das organizações sociais e internacionais em qualquer nível - econômico, político e epistêmico - e que se baseia em uma duvidosa ética: a justificação do extermínio, do envenenamento de águas e terras em prol do crescimento econômico".

Desse modo, é possível entender como o discurso científico se coloca como um dos modos de constituição da colonialidade: a colonialidade do saber. É a colonialidade do saber que nos faz entender porque o agronegócio tem o pleno domínio de pesquisas e publicações científicas, a serviço do discurso desenvolvimentista.

O M21 se utiliza do discurso científico que sempre esteve a serviço do discurso neodesenvolvimentista, como um discurso oponente, como o seu outro discursivo. Esta subversão de sentidos se mostra nos trechos 1 (Nós somos representantes das comunidades do Jaguaribe, da Chapada do Apodi e nós somos a região mais atingida com a questão de agrotóxico) e trecho 7 (Nós estamos no meio do povo. Nós estamos juntos com o projeto de lei. Estamos juntos contra a pulverização aérea totalmente). 
Nos dois trechos acima percebemos a utilização dos verbos "ser" e "estar". Na medida em que codificam significados sobre "estados de ser" (LÖWY 2004, p. 237), os verbos acima possibilitam a identificação do(a)s falantes com as comunidades da região Jaguaribe-Apodi: "nós somos representantes das comunidades do Jaguaribe, da Chapada do Apodi; nós estamos com o povo". Conforme Moreira (2015, p. 212) "as posições dos atores sociais no discurso constituem os estilos marcados semioticamente, os quais refletem a formação das identidades". O posicionamento dos atores em identificar-se com o território, com o seu povo, faz parte de um processo de constituição de identidades subalternas, por meio da prática de colocar-se como oprimido, do lado subalterno da diferença colonial. A avaliação da representante da comunidade e do militante do MST é feita por meio da apreciação negativa, que funciona como um discurso de denúncia: "nós somos a região mais atingida com a questão de agrotóxico" e “queremos aqui denunciar que tem gente trabalhando de forma análoga à escravidão”. A comparação como avaliação "análoga à escravidão" também aponta para significados identificacionais que constroem identidades subalternas de luta e resistência.

\section{CONSIDERAÇÕES FINAIS}

A Análise dos significados acionais, representacionais e significados identificacionais nas práticas discursivas do Movimento 21 permite-nos observar a retórica da fronteira que o movimento, constituindo identidades subalternas decoloniais e engajamento híbridos. Tais práticas permite-nos ampliar os conceitos de educação, rompendo a barreira do universo escolar. Se considerarmos a educação como processo social amplo que promove aprendizagens, conhecimentos e construção de saberes, o M21 se constitui em rica experiência educativa, caracterizada pela denúncia de injustiças e desigualdades sociais e pelo anúncio de nova sociabilidade entre os seres humanos.

Num contexto de classes sociais em disputa, a educação formal e não formal aponta para distintos projetos históricos nas lutas sociais, nos quais sujeitos sociais, em complexas relações, se educam objetiva e subjetivamente, produzindo saberes e práticas concernentes aos seus interesses políticos, econômicos e culturais (MENDES, 1993).

A práxis educativa que alça os oprimidos, as classes populares, a condição de sujeitos históricos se expande a vários espaços: movimentos sociais, escola, pastorais, intelectuais orgânicos, sindicatos, partidos, meios de comunicação etc. Alguns destes espaços como o M21 e seus sujeitos coletivos, se constituem em instrumentos voltados aos interesses dos 
trabalhadores e das trabalhadoras, portanto, bem definidos quanto à emancipação social; outros, como a escola e os meios de comunicação, são campos de disputa.

Desse modo, podemos dizer que o conjunto de ações de resistência dos diversos sujeitos sociais que atuam na Chapada e municípios do entorno, unificados no M21, produz uma diversidade de práxis educativas, sejam científicas, políticas, culturais e religiosas, com características relacionadas aos camposii de atuação de cada coletivo envolvido.

Recebido em: maio de 2015 Aprovado em: outubro de 2015 claudiana.alencar@uece.br sandra.gadelha@uece.br

\section{REFERÊNCIAS}

BONNEWITZ, Patrice. Primeiras Lições sobre a sociologia de P. Bourdieu. Petrópolis, RJ: Vozes, 2003

CARVALHO, Sandra Maria Gadelha de. Educação do campo: Pronera, uma política pública em construção. Tese Doutoramento, Universidade Federal do Ceará, Fortaleza, Brasil, 2006.

CARVALHO, Sandra Maria Gadelha de; MENDES, José Ernandi. Práxis educativa do Movimento 21 na resistência ao agronegócio In: Interface Journal. INSS: 2009-2431.

http://www.interfacejournal.net/2014/06/interface-volume-6-issue-1-movement-pedagogies/ (pp. $45-73), 2014$.

CARVALHO, Sandra Maria Gadelha de; PIO, Paulo Martins \& MENDES, José Ernandi. Práxis e prática educativa em Paulo Freire: reflexões para a formação e a docência. XVII ENDIPE - Encontro Nacional de Didática e Prática de Ensino, Fortaleza: 2014.

EGGINS, Suzanne. An introduction to systemic functional linguistics. New York - London: Continuum, 2004.

FAIRCLOUGH, N. A dialectical-relational approach to Critical Discourse Analysis in social research. In: WODAK, R.; MEYER, M. (Orgs.) Methods of Critical Discourse Analysis. Londres: Sage, 2009, pp. 162-186.

Analysing discourse: textual analysis for social research. London: Routledge, 2003.

. Discurso e mudança social. Brasília: Editora da Universidade de Brasília, 2001[1992].

FERREIRA, Marcelo José Monteiro. Contribuições epistemológicas/metodológicas para o fortalecimento de uma (cons) ciência emancipadora. Dissertação de Mestrado em Saúde Pública. Universidade Federal do Ceará, Fortaleza, Brasil, 2012.

FRIEDMAN, S. O «falar da fronteira», o hibridismo e a performatividade: teoria da cultura e identidade nos espaços intersticiais da diferença. In: Revista Crítica de Ciências Sociais, 61, pp. 5-28, 2001.

GROSFOGUEL, Ramón. Para descolonizar os estudos de economia política e os estudos póscoloniais: Transmodernidade, pensamento de fronteira e colonialidade global In: SANTOS, 
Boaventura de Sousa; MENESES, Maria Paula. (Orgs.) Epistemologias do Sul. Coimbra: Edições Almedina, 2009.

LÖWY, Michael. Écosocialisme: l'alternative radicale à la catástrofe écologique capitaliste. Paris: Mille et Une Nuits, 2011.

MAGALHÃES, I. Teoria crítica do discurso e texto. Linguagem em (Dis)curso, 4 (especial): 113-131, 2004.

MALDONADO- TORRES, Nelson. A topologia do Ser e a geopolítica do conhecimento. Modernidade, império e colonialidade In: Revista Crítica de Ciências Sociais, 80, Março 2008: 71114.

MARX, Karl \& ENGELS, Friedrich. A ideologia Alemã. Disponível em 29/05/2015.

https://www.marxists.org/portugues/marx/1845/ideologia-alema-oe/cap2.htm. 2015.

MENDES, José Ernandi. Relação entre saberes In: Revista Educação em Debate. Ano 15, n. 23-2425-26. Fortaleza/CE: EUFC, 1992/1993.

MIGNOLO, Walter. Local Histories/Global Designs: Essays on the Coloniality of Power, Subaltern Knowledges and Border Thinking. Princeton: Princeton University Press, 2000.

MOREIRA, Miguel Almeida. A gramática da experiência de adolescentes sobre o lugar onde vivem. In: Cadernos de Linguagem e Sociedade, 16(1), 2015.

QUIJANO, Aníbal. Colonialidade do poder, eurocentrismo e América latina. in: LANDER, Edgardo (Org.). A colonialidade do saber: eurocentrismo e ciências sociais. buenos Aires: Consejo latinoamericano de Ciencias Sociales (ClACSO), 2005. p. 227-278.

Colonialidade do poder e classificação social. In: SANTOS, Boaventura de Sousa;

MENESES, Maria Paula (Orgs). Epistemologias do Sul. Coimbra: Edições Almedina S.A., 2009. p. $73-118$.

RIGOTTO, Raquel (Org.). Agrotóxicos, trabalho e saúde: Vulnerabilidade e resistência no contexto da modernização agrícola no Baixo Jaguaribe/CE. Fortaleza: Ed.UFC, 2011.

SOUSA SANTOS, Boaventura de e MENESES, Maria Paula (Orgs). Epistemologias do Sul. Coimbra: Edições Almedina, 2009.

VÁZQUEZ, A. Sánchez. Filosofia da práxis. Rio de Janeiro: Paz e Terra, 1977.

WHITE, P. R. R. Appraisal. In: ZIENKOWSKI, J.; ÖSTMAN, J.-O.; VERSCHUEREN, J. (Orgs.) Discursive Pragmatics. Amsterdam: John Benjamins, 2011.

\footnotetext{
'Ver Site do TRAMAS - http://nucleotramas.webnode.com.br/

ii Os campos são “...lugar de uma lógica e necessidades específicas. Por exemplo, o campo artístico, o campo religioso, ou o campo econômico obedecem a lógicas diferentes” (Bourdieu apud Bonnewitz, 2003, p.60).
} 